\title{
Observed daily large-scale rainfall patterns during BOBMEX-1999
}

\author{
A K Mitra*, M Das Gupta, R K Paliwal and S V Singh \\ National Centre for Medium Range Weather Forecasting, Mausam Bhavan Complex, Lodi Road, \\ New Delhi 3, India. \\ *e-mail: akm@ncmrwf.gov.in
}

A daily rainfall dataset and the corresponding rainfall maps have been produced by objective analysis of rainfall data. The satellite estimate of rainfall and the raingauge values are merged to form the final analysis. Associated with epochs of monsoon these rainfall maps are able to show the rainfall activities over India and the Bay of Bengal region during the BOBMEX period. The intra-seasonal variations of rainfall during BOBMEX are also seen using these data. This dataset over the oceanic region compares well with other available popular datasets like GPCP and CMAP. Over land this dataset brings out the features of monsoon in more detail due to the availability of more local raingauge stations.

\section{Introduction}

Organised convection over the Bay of Bengal and adjoining areas during the summer monsoon is related to the air-sea coupled processes and also gets reflected in the intra-seasonal variability of rainfall. To understand these processes properly during BOBMEX-99, field campaign, several atmospheric and oceanic observations were collected over the Bay of Bengal region during the summer monsoon of 1999. These datasets collected from the field experiments are very valuable, as they require special effort in terms of financial expense and the cost of manpower. Individual scientists and research institutes use these special datasets to understand different physical processes in the atmosphere and ocean, and the connected dynamical processes. Generally, during field experiments several ships, buoys, air-crafts, satellites and special observing stations are engaged to generate data at different locations simultaneously. This variety of data spread over a region provides an opportunity to link the processes of different scales in the atmosphere and ocean. In a monsoon type environment (BOBMEX) the meso-scale convec- tive systems are highly coupled to the large-scale environment with two-way interactions. Hence it becomes very important to also have meteorological data related to the large-scale monsoon flow. In this context the objectively analysed values of different meteorological variables on a regular grid (from NWP centers) become very useful for the complete scientific study of the processes of interest along with the field measurements. Rainfall is the most important parameter for monsoon process studies. Large-scale precipitation datasets are being prepared independently at various meteorological centers to augment the atmospheric grid point analyses of various parameters (multi year reanalyses) for climate related studies (Huffman et al 1995; Xie and Arkin 1996; Gruber et al 2000). During MONEX field experiments Krishnamurti et al (1983) prepared a rainfall atlas which was very useful. In this study, a dataset of daily rainfall was prepared for the Indian monsoon region, coinciding with the phase I and phase II of BOBMEX-99. These data will help various researchers working with other BOBMEX datasets to understand the interaction of the local processes with the largescale monsoon environment. Apart from the cli-

Keywords. BOBMEX; rainfall analysis; monsoon; Bay of Bengal; convection. 
mate studies, daily rainfall data can be used to understand the coupled monsoon system at various scales. Another important use of this rainfall dataset is to validate the tropical rainfall precipitation produced by atmospheric general circulation models for various studies.

\section{Data and methodology}

At the satellite meteorology division of IMD, IR data from INSAT is used for deriving the rainfall amounts from cloud top temperatures by 'GOES Precipitation Index' (GPI) technique. For the Indian region, every three-hourly IR data were used to compute the rainfall rates on $2.5^{\circ}$ latitude by $2.5^{\circ}$ longitude grids. The accumulation of these three-hourly rainfall rates (eight sets per day) gives the one-day total rainfall for the said region (Arkin et al 1989) valid at 03 UTC. This daily rainfall is interpolated to a $1.5^{\circ}$ latitude by $1.5^{\circ}$ longitude grid bi-linearly and serves as the first guess of the objective rainfall analysis system. Conventional raingauge values are merged with the first guess to produce the final rainfall analysis. An objective analysis scheme (Mitra et al 1997) is used to prepare grid point values of 24 hours accumulated observed rainfall over the Indian region and the adjoining oceanic regions at a resolution of $1.5^{\circ}$ latitude by $1.5^{\circ}$ longitude grids by merging the satellite and raingauge data.

\section{Rainfall during BOBMEX}

This study does not intend to explain the rainfall variability, but rather describes it and makes a rainfall dataset and maps available to study this complex monsoon system in conjunction with the other datasets collected during the BOBMEX field experiment. The observed changes in the rainfall patterns during the different weeks discussed here are mainly due to the changes in the monsoon flow patterns, which are associated with the variability (active/weak) of the complex monsoon system.

In this study forty-five days of daily rainfall maps were produced covering the full period of BOBMEX phase I and phase II. From these daily maps the rainfall information is presented in a variety of ways. Figure 1 shows two sample cases of satellite derived, and the corresponding final merged, rainfall for active (6th August) and weak (23rd August) cases. On 6th August the satellite rainfall shows a lot of spread near the monsoon trough region, and near the west coast of India the heavy rainfall is not captured. When the raingauge data are merged with satellite data the west coast rain is captured well, and the spreading of the rainfall near the monsoon trough region is decreased. Therefore the merging of gauge data including the data reporting no rain is very important to make the final merged dataset. Figures 2 and 3 show the total weekly rainfall amounts for different weeks in progression during the BOBMEX period. During the first week (15th July-21st July) the west coast rainfall maxima is $55 \mathrm{cms}$ and the north Bay of Bengal had a maxima of $15 \mathrm{cms}$. During this week a low pressure system formed over the head Bay of Bengal, moved north westward and merged with the monsoon trough on 16 th July. Strong surface winds were noticed there. The strong wind zone of the 'Low Level Jet' (LLJ) of the Arabian Sea was seen around $13^{\circ} \mathrm{N}$ latitude. A pressure gradient of $10 \mathrm{hPa}$ over the Indian subcontinent was also seen during this week. In the next week also (22nd July-28th July) the monsoon was active and the Bay rainfall increased to $20 \mathrm{cms}$. The rainfall activity was also enhanced along the monsoon trough. The strong wind zone of LLJ moved to $16^{\circ} \mathrm{N}$ latitude. Another low pressure system formed in the head Bay region and intensified to a deep depression by 28th July. One westerly system was also passing through northwest India this week, resulting in moderate rainfall in north India along the foothills due to it's interaction with the lower level easterlies of the monsoon system. In the third week (29th July-4th August) rainfall activity along the west coast as well as over the Bay of Bengal was reduced. The west coast maxima was only $20 \mathrm{cms}$ and the rainfall over the Bay and adjoining areas was also reduced. The Bay of Bengal monsoon flow was weak. The low pressure system of the previous week reached up to northwest Madhya Pradesh by 30th July. It further moved up to west Rajasthan by 3rd August resulting in a good amount of rainfall along it's track. A second low pressure formed over the head Bay on 31st July and moved towards northwest reaching Madhya Pradesh by 4th August. During the fourth week (5th-11th August) monsoon became again stronger with heavy rainfall along the west coast and head Bay region. In the west coast two separate maximas were seen with $15 \mathrm{cms}$ and $35 \mathrm{cms}$ respectively. The head Bay showed $20 \mathrm{cms}$ of rainfall. A low pressure system formed on 5th August over the head Bay and intensified to depression by 7th August and crossed the West Bengal coast. By 10th August the low pressure system was situated over Madhya Pradesh. In the Bay of Bengal strong winds were reported from the Sagar Kanya ship. During the fifth week (12th August-18th August) the monsoon activity over the Indian land mass was suppressed. The pressure gradient along the west coast was reduced. Weak monsoon flow conditions were seen in the Bay of Bengal. During 

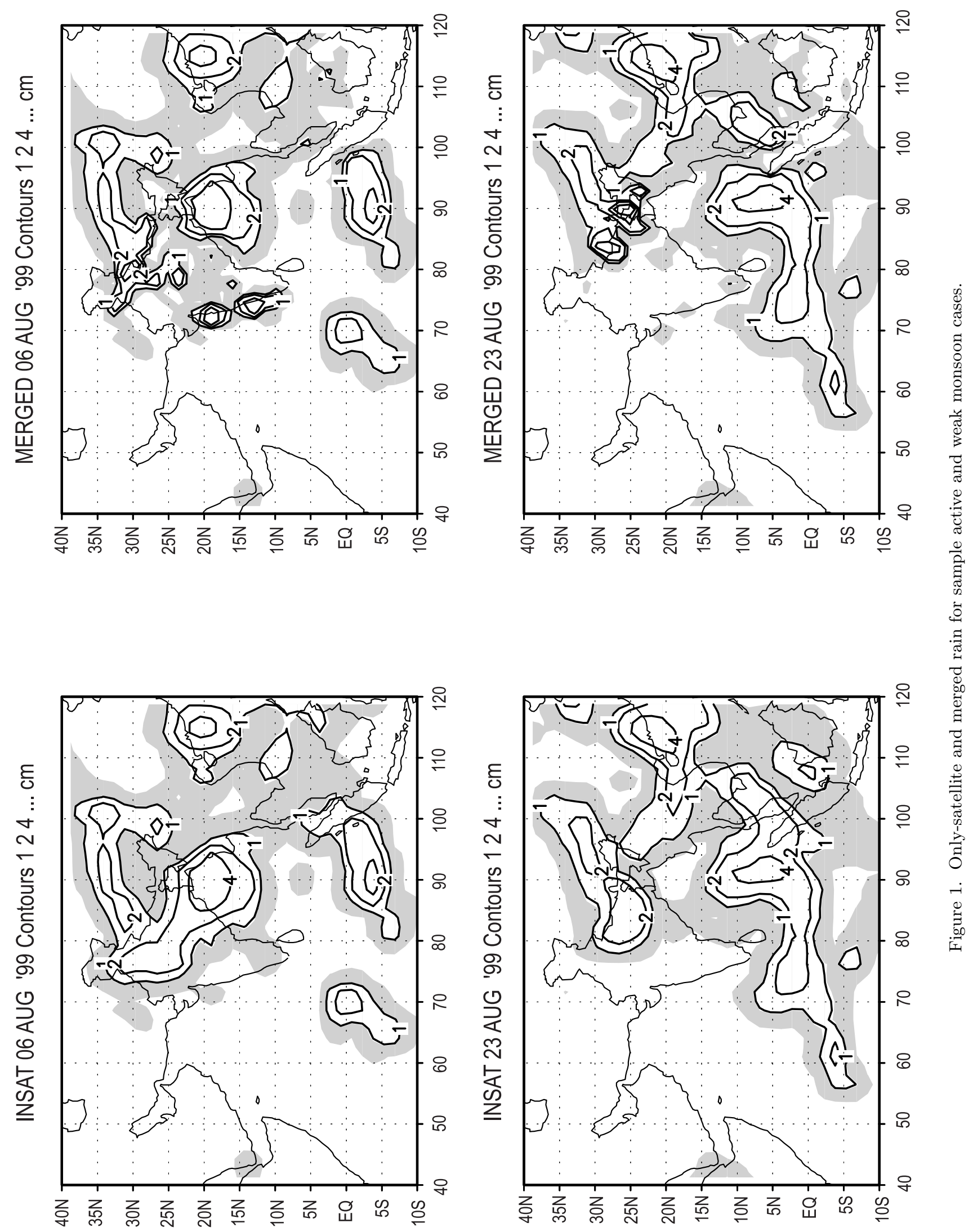

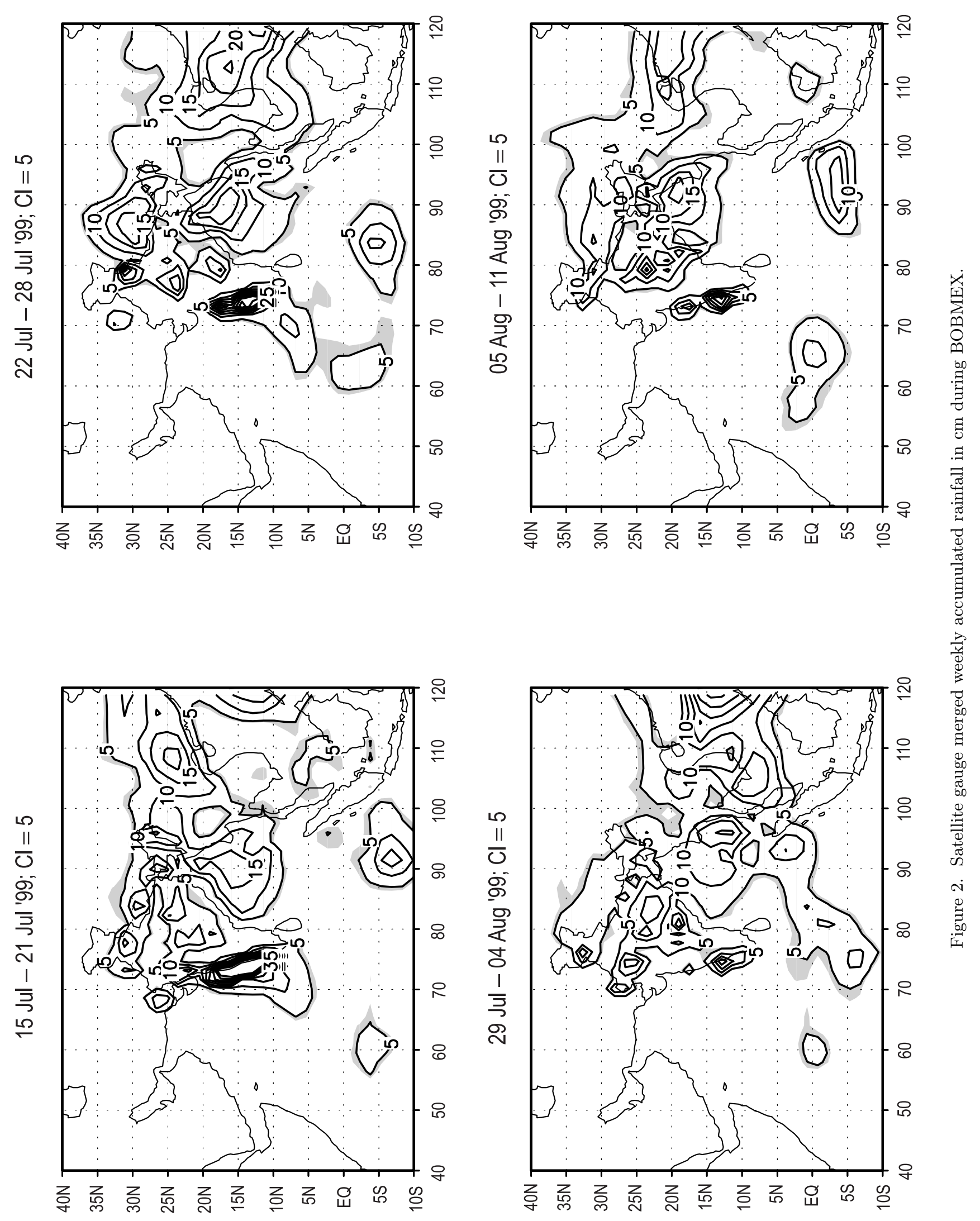

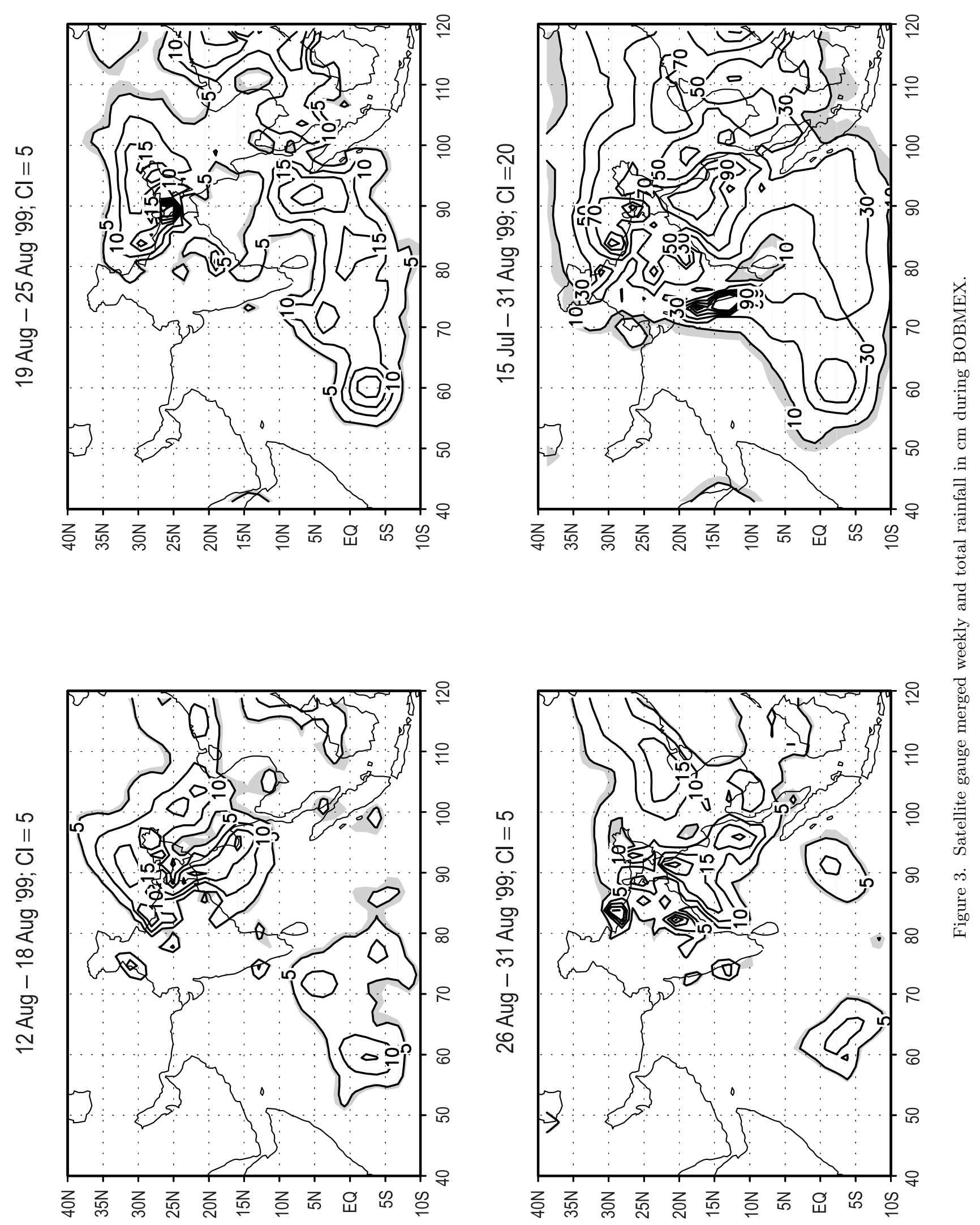

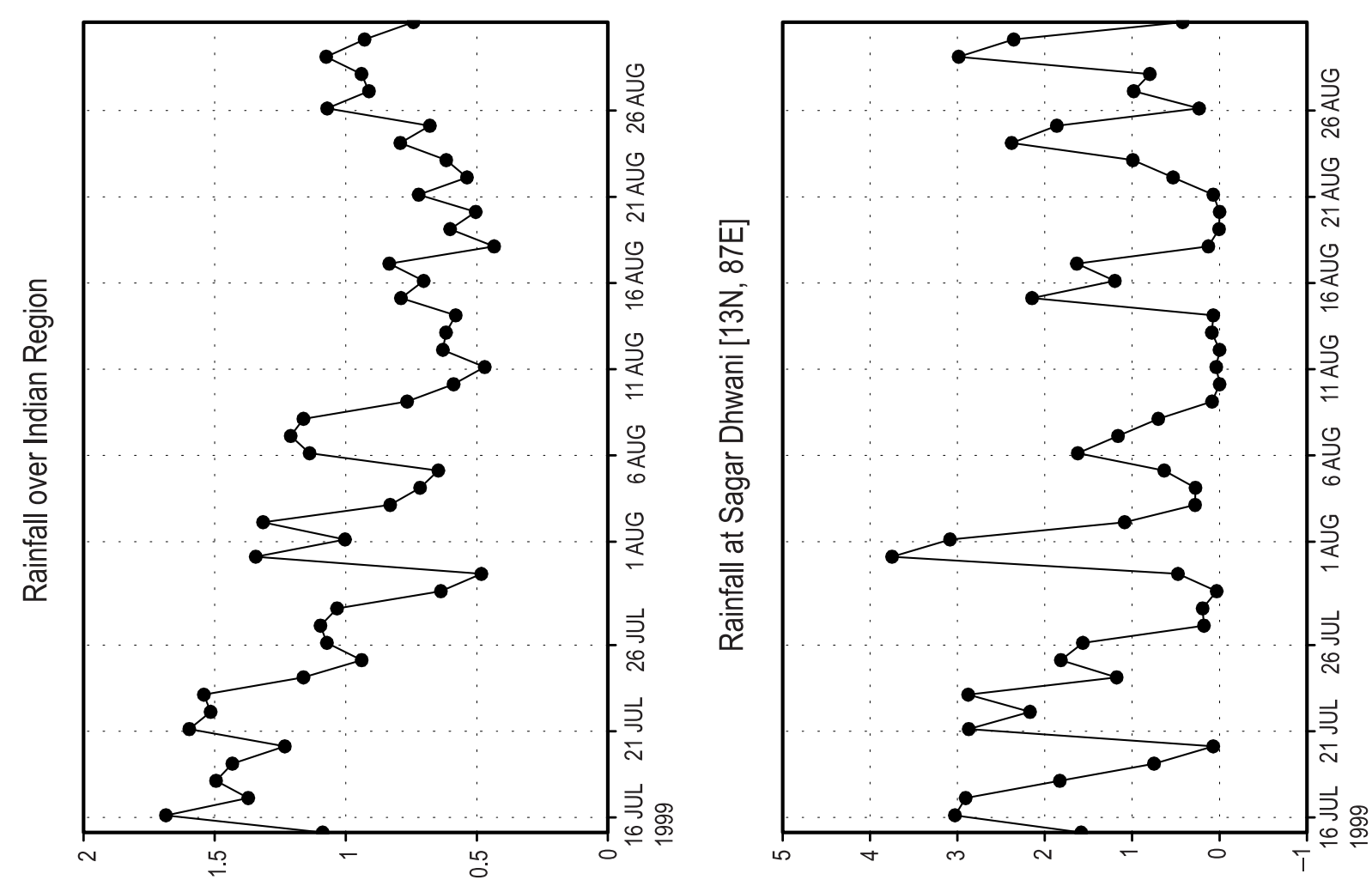

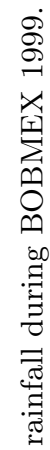
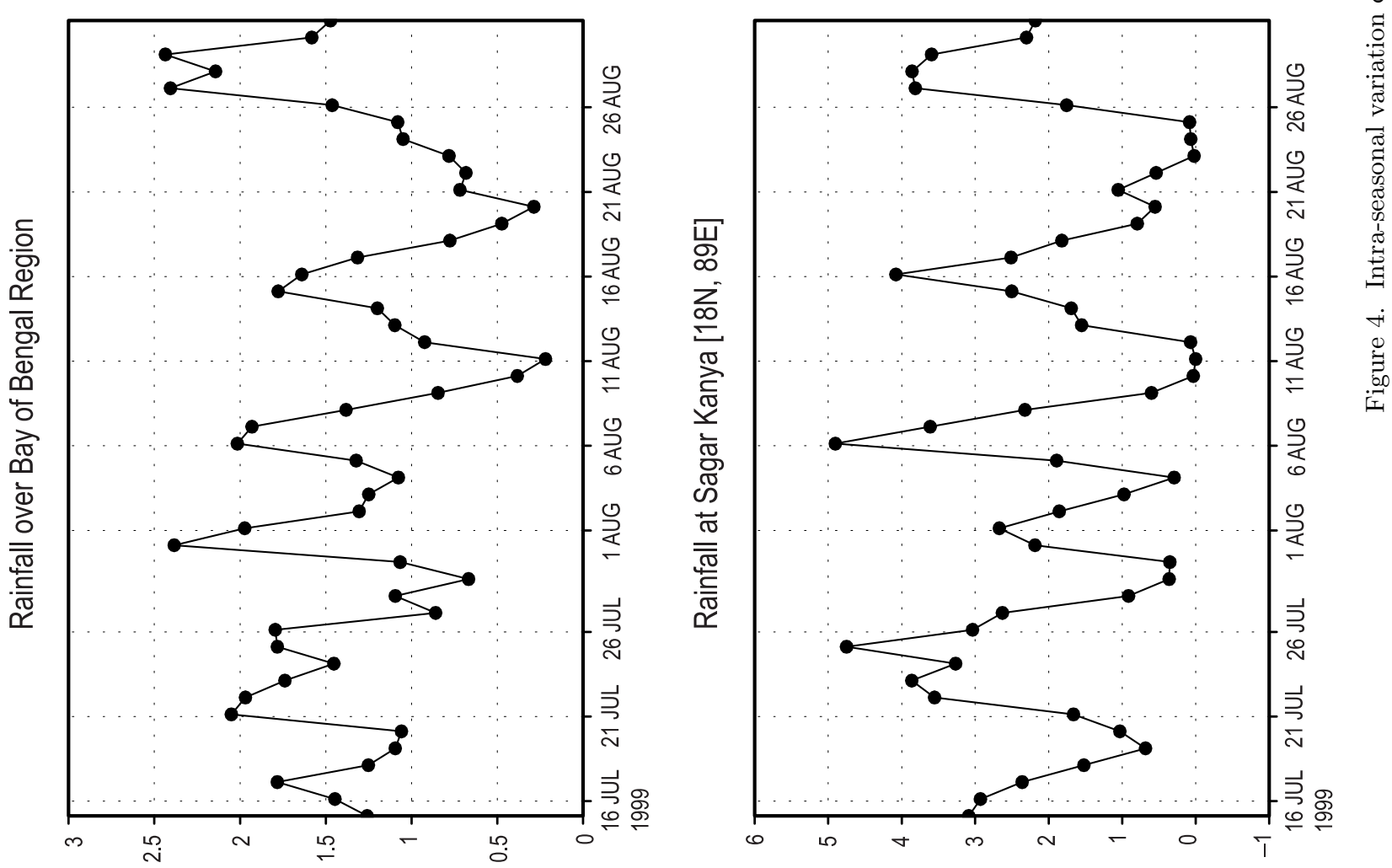
Observed rainfall cm/day Av [80E - 90E]

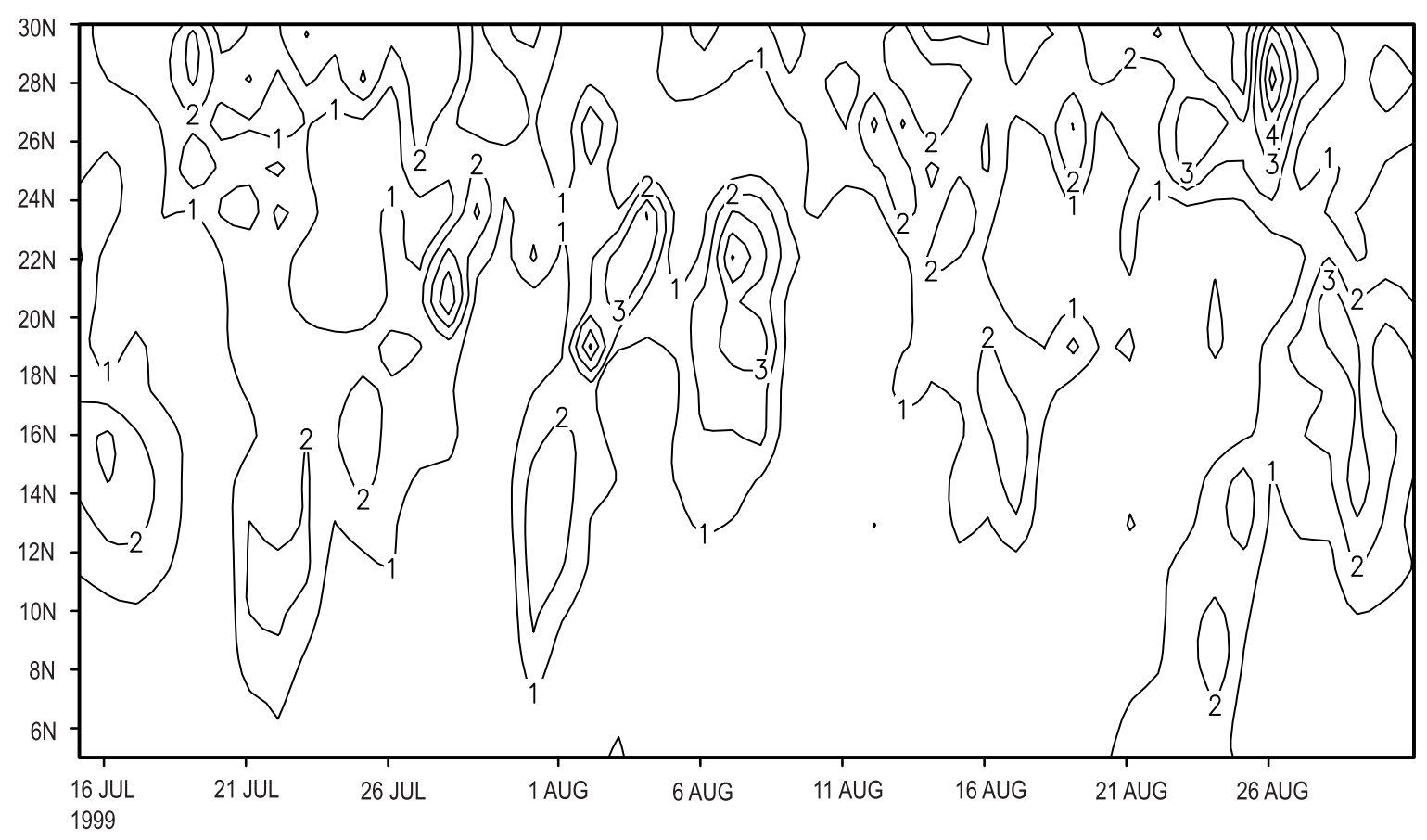

Observed rainfall cm/day Av [70E - 80E]

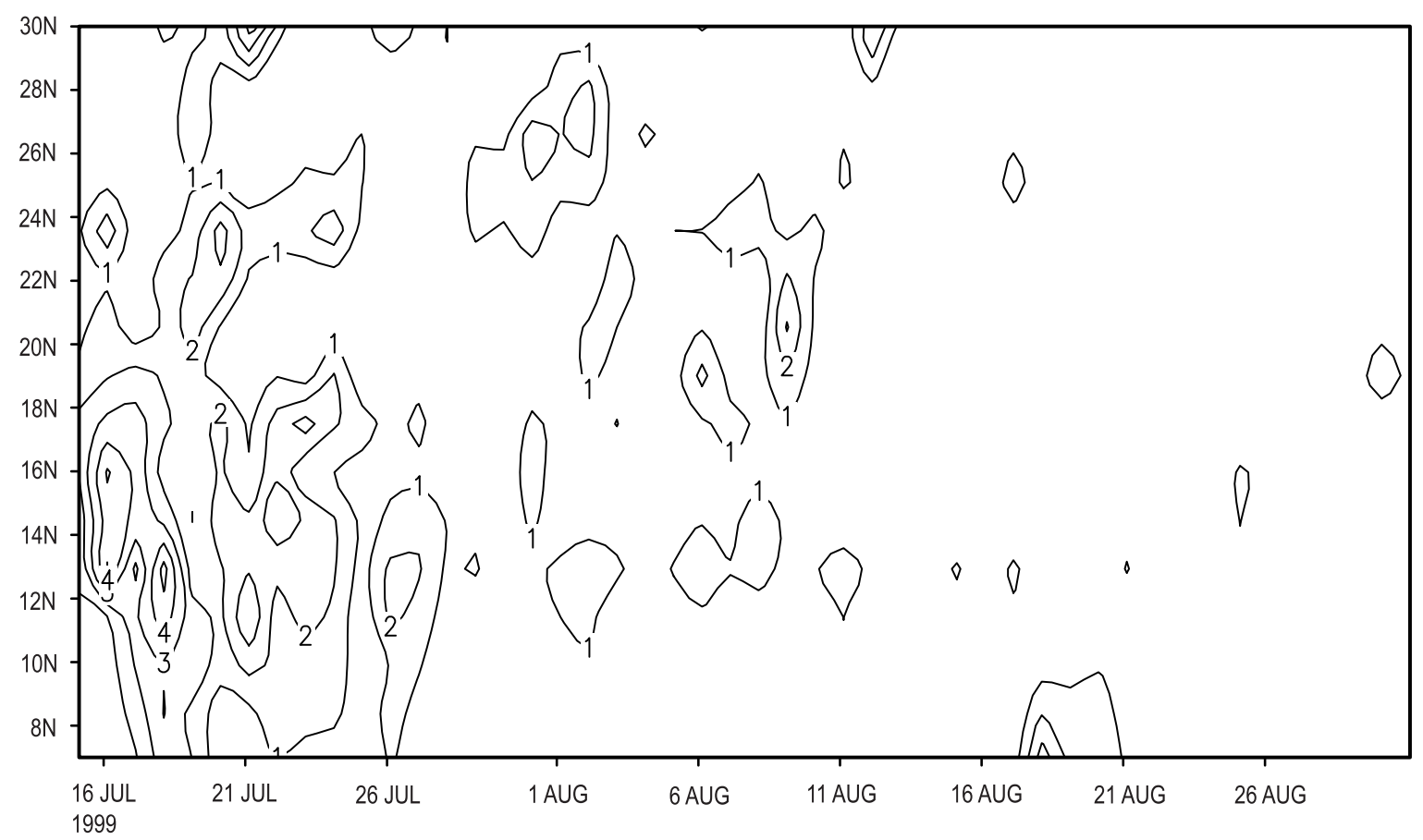

Figure 5. Latitude days cross section of rain during BOBMEX.

this week monsoon winds continued to decrease. There was almost no rainfall over the land and the rainfall band moved to the foothills with a rainfall maxima of $15 \mathrm{cms}$. The sixth week (19th August25th August) the rainfall activity continued to remain low with rainfall maxima of $35 \mathrm{cms}$ at foothill region. Weak monsoon conditions continued till 22nd August. The monsoon trough was not seen in the lower troposphere. During the last week (26th August-31st August) a low pressure system formed over west central Bay on 26th August and reached north Bay by 27th August. It appeared 
Rainfall 16 Jul -5 Aug ' $99, \mathrm{Cl}=10 \mathrm{~cm}$

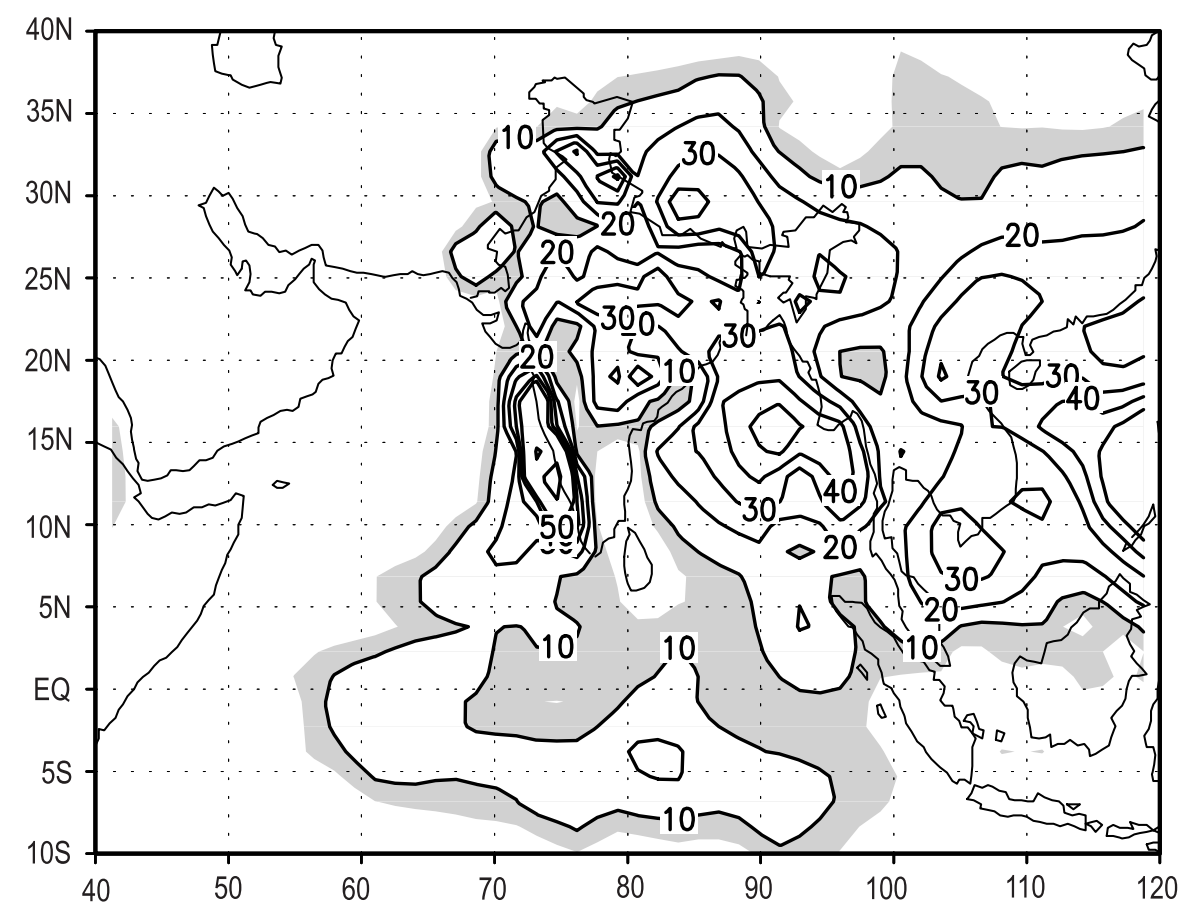

Rainfall 6 Aug -31 Aug ' $99, \mathrm{Cl}=10 \mathrm{~cm}$

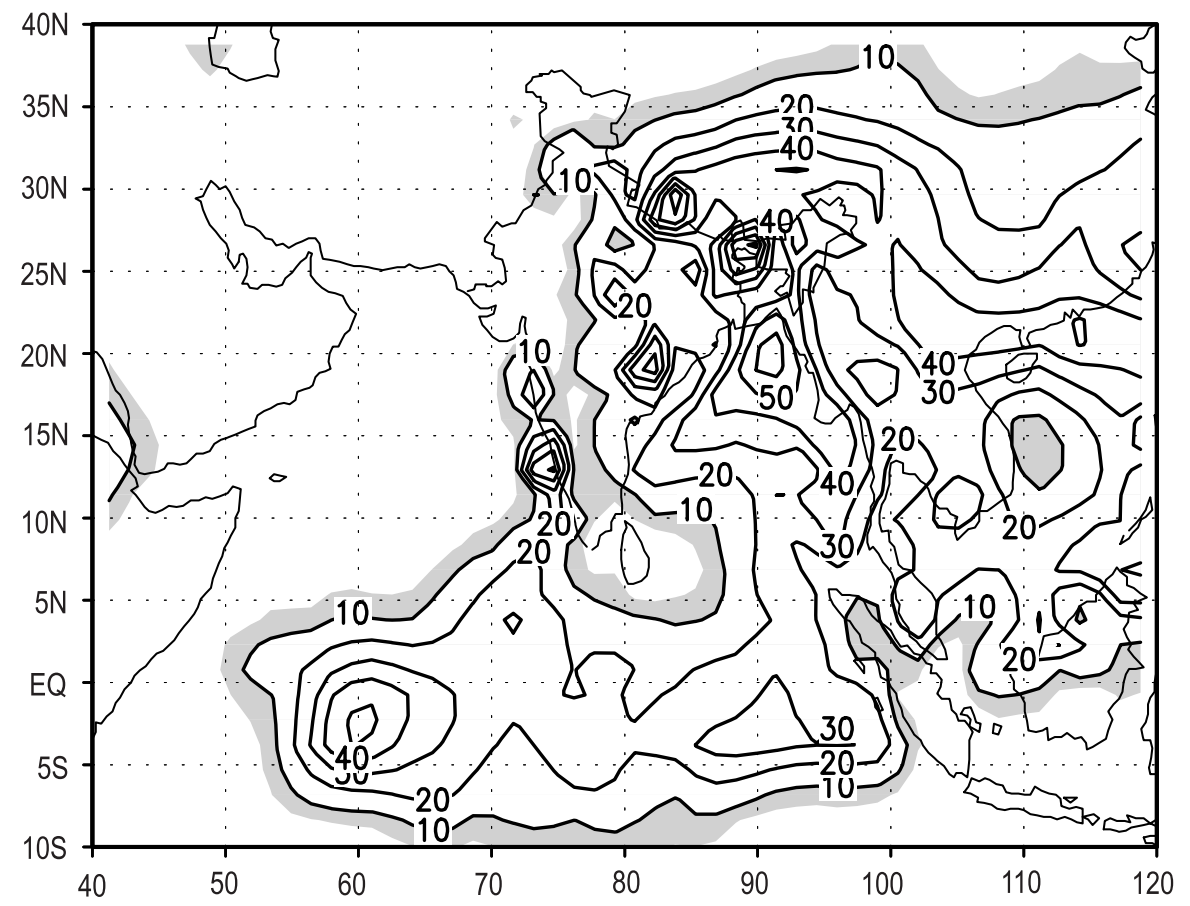

Figure 6. Satellite gauge merged rainfall during BOBMEX.

like a revival of monsoon in the Bay of Bengal. The head Bay, foothills and east coast had regions with rainfall maxima of $25 \mathrm{cms}$. This week also had very less rainfall along the west coast. The last frame of figure 3 shows the total accumulated rainfall for the whole BOBMEX period. During this whole period the rainfall maxima over the west coast was $160 \mathrm{cms}$, head Bay $90 \mathrm{cms}$, foothills $110 \mathrm{cms}$ and along the monsoon trough region $50 \mathrm{cms}$. Figure 4 shows the intra-seasonal variation of rainfall over the Bay of Bengal $\left(84^{\circ} \mathrm{E}-95^{\circ} \mathrm{E} ; 10^{\circ} \mathrm{N}-22^{\circ} \mathrm{N}\right)$ and over the Indian region $\left(70^{\circ} \mathrm{E}-90^{\circ} \mathrm{E} ; 10^{\circ} \mathrm{N}-30^{\circ} \mathrm{N}\right)$ 

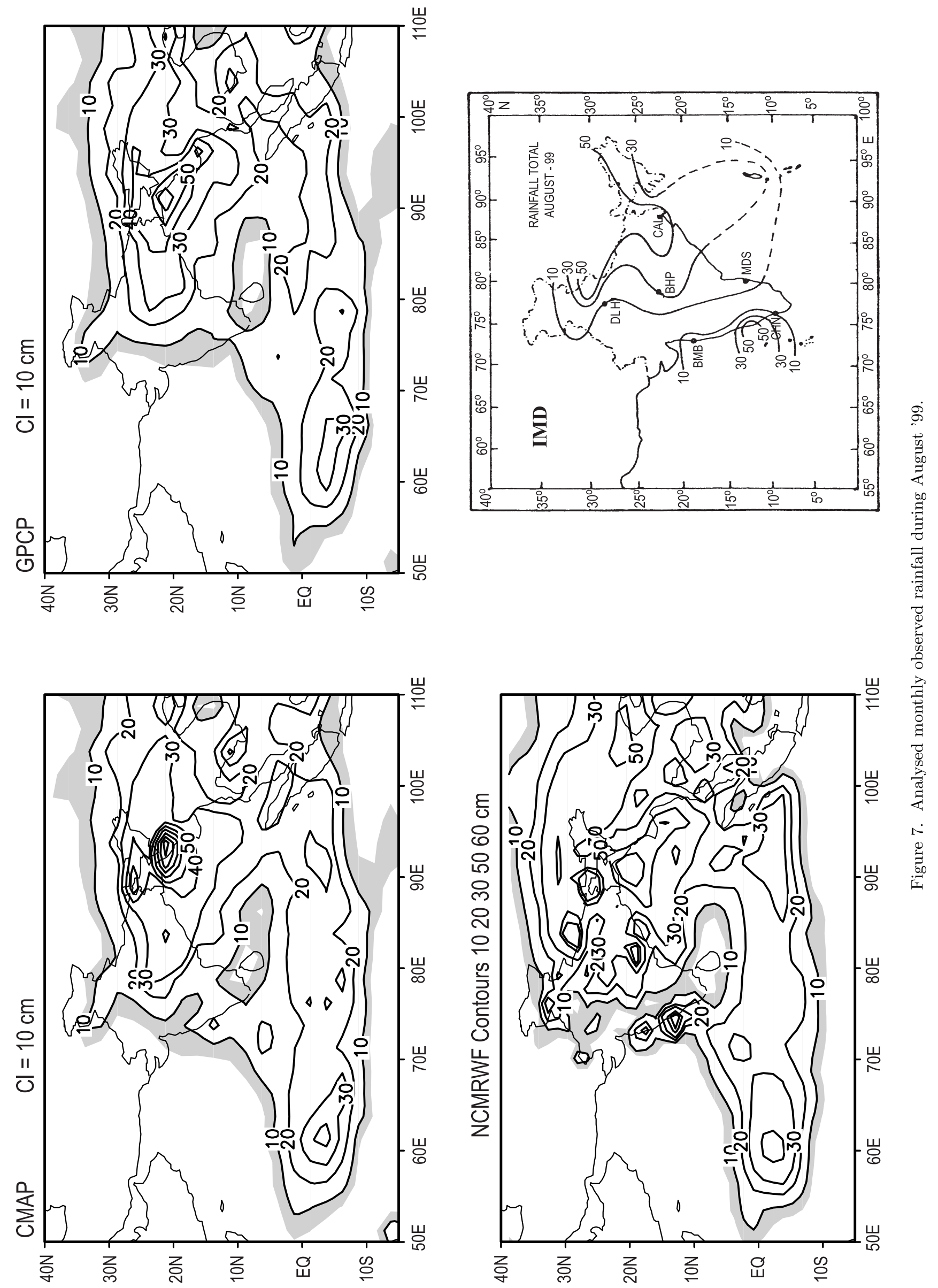
during the BOBMEX period along with the rainfall variation at Sagar Kanya and Sagar Dhwani ship locations. As expected, considerable intra-seasonal variations are seen in all the locations. Figure 5 shows the latitude-day cross section of rainfall for the Bay of Bengal and Indian region for the BOBMEX period. There were five epochs of active rainfall over the Bay of Bengal region with only one event showing a slight northward movement of the rainfall band. But over the land region, the rainfall activity was very less for the whole month of August 1999. It may be noted that the averaging area near the west coast is considered only up to $80^{\circ} \mathrm{E}$, so that the rainfall associated with lows over Orissa and east coast is excluded. The land rainfall only indicated the flow over the west coast showing the strength of large-scale monsoon (LLJ). In figure 6 the rainfall roughly corresponding to phases I and II of the BOBMEX experiment respectively are shown. One can clearly see that during phase II the rainfall activity over the west coast and along the monsoon trough had reduced. But the head Bay region remained active during both the phases.

GPCP (Huffman et al 1995) and CMAP (Xie and Arkin 1996) are the two other popular datasets widely used by weather and climate scientists for monsoon research. A comparison of the two datasets by Gruber et al (2000) revealed that in general for the large-scale rainfall pattern there is good agreement between the two datasets, but there are regions where the agreement is not good. To check the credibility of NCMRWF analysed dataset, it is compared with the GPCP and the CMAP values. Figure 7 depicts the comparison of NCMRWF dataset for the month of August '99 with the GPCP, CMAP and also with the IMD analysis (IMD, 1999). The heavy rainfall seen near the west coast in IMD analysis is matching well with the NCMRWF analysis. Both in the GPCP and the CMAP analysis the west coast rain is not captured. The rainfall over the oceanic region is matching well in all the three analyses.

\section{Conclusions}

For the Indian region, a daily rainfall dataset and the corresponding rainfall maps are produced by merging operationally available satellite rainfall estimates and raingauge data. These maps are able to depict the rainfall activities over the Bay of Bengal region during the BOBMEX period. These data are able to show the intra-seasonal variation of rainfall during BOBMEX. The latitude-day cross section of rainfall charts indicates the epochs of active and breaks in rainfall activity over the land and the Bay of Bengal region. When compared with the other available popular datasets like GPCP and CMAP, the NCMRWF analysed rain datasets are found to be of a good standard. NCMRWF analysis also matches well with the IMD analysis for the study period. These rainfall maps will be helpful in interpreting various other data obtained from the BOBMEX field experiments. This type of a daily merged dataset may be prepared for longer periods under the 'Indian Climate Research Program'.

Note: The dataset described in this paper is available at NCMRWF ftp site. One can log in to ftp.ncmrwf.gov.in with 'anonymous' user-id and e-mail address as the password. The data along with the READ fortran program is kept in the directory '/pub/outgoing/bobmex/pptn'.

\section{Acknowledgement}

We are thankful to IMD for providing rainfall estimates from INSAT IR data. Thanks are also due to the scientists of GPCP and CMAP groups for making their data available via ftp. Suggestions from two anonymous reviewers helped in improving the content of the paper.

\section{References}

Arkin P A, Rao A V R K and Kelkar R R 1989 Large-scale precipitation and OLR from INSAT-1B during the 1986 southwest monsoon season; J. Climate 2 619-628

Huffman G J, Adler R F, Rudolf B, Schneider U and Keehn P R 1995 Global precipitation estimates based on a technique for combining satellite based estimates, raingauge analysis, and NWP model precipitation information; J. Climate 8 2810-2823

Gruber A, Su X, Kanamitsu M and Schemm J 2000 The comparison of two merged raingauge-satellite precipitation dataset; Bull. Am. Met. Soc. 81(11) 2631-2644

India Meteorological Department 1999 Climate Diagnostic Bulletin of India - August 1999: Near Real Time Analysis; Report of National Climate Centre, ADGM(R), 19 pages, issue no. 42, IMD, Pune, India.

Krishnamurti T N, Cocke S, Pasch R, Low-Nam S 1983 Precipitation estimates from rain gauge and satellite observations, summer MONEX, FSU Report: 83-7, Dept. of Meteorology, Florida State University, USA., 373pp

Mitra A K, Bohra A K and Rajan D 1997 Daily rainfall analysis for Indian summer monsoon region; Int. J. Climatology 17 1083-1092

Xie P P and Arkin P A 1996 Analyses of global monthly precipitation using gauge observations, satellite estimates, and numerical model prediction; J. Climate 9840 858 